\title{
Research on Logistic Distribution Routing Based on Improved Ant Colony Algorithm
}

\author{
Zheng Jun ${ }^{1, a}$ \\ ${ }^{1}$ Baotou Teachers' College Network Information Center;Baotou, Inner Mongolia, 014030, China \\ azhengjun_025@163.com \\ (Baotou Teachers' College Network Information Center; Baotou, Inner Mongolia, 014300, China)
}

KeyWords: logistic distribution; ant colony algorithm; route solution

\begin{abstract}
Logistic distribution is one the most important parts in logistic industry, its core is to get the shortest transportation route of car. This paper makes mathematical modeling on distribution route of logistic car, constructs target function and constraint condition. It makes analysis on realization and mathematical modeling of the traditional ant colony algorithm. As for the shortcomings of traditional ant colony algorithm, this paper puts forward to apply genetic algorithm into improved ant colony algorithm of its route option, and it also gives detailed realization steps. It makes simulation experiment under experiment environment and analyzes performance of traditional ant colony algorithm and improved ant colony algorithm through comparison and analysis of experiment technology data. The experiment indicates that the improved ant colony algorithm has higher astringency and search function in aspect of exploring logistic distribution logistics.
\end{abstract}

\section{Introduction}

Under the acceleration by quick development of Chinese economy in recent years, logistic industry has obtained drastic development. The core of logistic industry is logistic distribution, including parts such as goods dispatching, goods distribution and goods delivery etc and goods delivery is the core part in these parts. According to relevant investigation result by China Association of Warehouses and Storage, the transportation fees in logistic all accounts for more than $50 \%$ in raw material logistic, end product logistic and business logistic. Therefore, optimizing dispatch and reasonable choosing route has become to be the important measures ${ }^{[1-2]}$ to shorten cost as well as increase revenue and efficiency.

Theoretically, optimization and dispatching problems on distribution car belong to NP-Hard problems; many scholars have made plenty of exploratory researches on these problems in recent years. Of which, ant colony algorithm is the most obvious; it presents the superior function in aspects of solving larger NP-Hard problems. However, the traditional ant colony algorithm has slow convergence rate in aspect of finding optimal distribution route in logistic and it is easily to fall into defects of locally optimal solution. Therefore, this paper makes improvement on traditional ant colony algorithm on the basis of making deep research on ant colony algorithm; it strengthens its convergence performance, designs simulation experiment and makes demonstration on algorithm after improvement.

\section{Realization theory of ant colony algorithm}

Through research on bionics, ant will find out the shortest route from nest to food according to the message element left on the route. Inspired by this, Italy scholar M.Dorigo put forward artificial ant colony algorithm. The following diagram 1 will intuitively describe its route choice principle. 


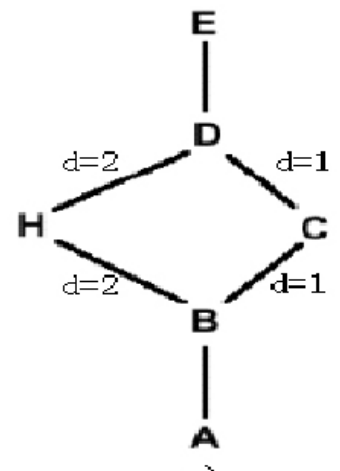

a)

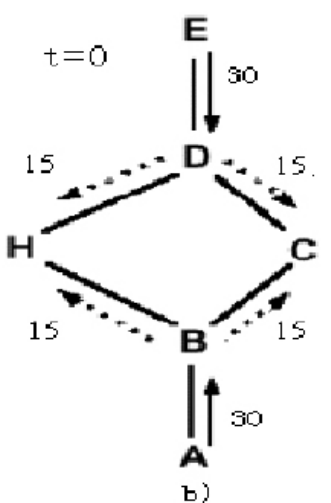

b)

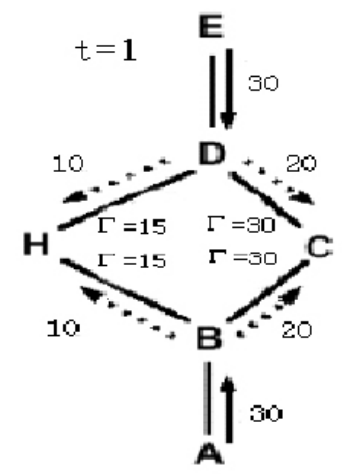

c)

Diagram 1 Schematic diagram of ant colony algorithm realization

Suppose A is ant nest, E is food point, C, B, D, H are route points. The distance between route $\mathrm{BC}$ and $\mathrm{CD}$ are all 1, distance of route $\mathrm{BH}$ and $\mathrm{HD}$ are all 2, make 30 ants seek food at the same time. It is indicated by diagram $1 \mathrm{a}$.

At time when $\mathrm{t}=0$, every route has no message element, the probability of ant choosing every route is the same. As it is indicted by diagram 1.b, there are 15 ants choose BHD route and 15 ants choosing BCD route. Ant will leave message element on the route it passes by, and message element will volatilize with times goes by. Suppose the advancement progress of every ant is 2 , release and volatilization speed of message element are 1 per unit, then $t=1$ at the next time, the message element accumulated in route DCB is 30, the message element accumulated in route DHB is 15 . This when 30 ants return to ant nest A again, there are 10 ants choosing route DHB and 20 ants choosing route DCB, as it is indicated by diagram 1.c. With time goes on, message elements will gradually strengthening and volatilizing on the route, finally, it can find out the shortest route ABCDE from ant nest to food.

\section{Mathematical model of traditional ant colony algorithm}

Ant colony algorithm is established ${ }^{[3-4]}$ according to bionics characteristic for ant to seek food; its mathematical model is as follows:

Command $\mathrm{M}$ indicate the number of ant, $t$ indicates time, $\tau_{\mathrm{ij}}(\mathrm{t})$ indicates message element intensity of route $(\mathrm{i}, \mathrm{j})$ on time t. Ant colony algorithm makes route construction according to the following models:

The construction model of ant route is as follows:

$$
\mathrm{p}_{\mathrm{k}}(\mathrm{i}, \mathrm{j})=[\tau(\mathrm{i}, \mathrm{j})] \cdot[\eta(\mathrm{i}, \mathrm{j})]^{\beta} /\left(\sum_{\mathrm{SEJ} \mathrm{J}_{\mathrm{k}}(\mathrm{i})}[\tau(\mathrm{i}, \mathrm{s})] \cdot[\eta(\mathrm{i}, \mathrm{s})]^{\beta}\right), \mathrm{j} \in \mathrm{J}_{\mathrm{k}}(\mathrm{i}) 。
$$

Ant will leave message element when passing by route, message element will update according to the following model:

Updating model of message element:

$$
\tau_{\mathrm{ij}}(\mathrm{t}+\mathrm{n})=\rho \tau_{\mathrm{ij}}(\mathrm{t})+\Delta \tau_{\mathrm{ij}}, \Delta \tau_{\mathrm{ij}}=\sum_{\mathrm{k}=1}^{\mathrm{M}} \Delta \tau_{\mathrm{ij}}^{\mathrm{k}}
$$

1- $\rho$ indicates the volatilization degree between time $t$ and time $(t+n), \Delta \tau_{i j}$ indicates the message element intensity left on route $\mathrm{L}(\mathrm{i}, \mathrm{j})$ by ant in this operation.

If certain route has not been chosen by any ant, then message element on this route will be released. Its release model is as follows:

Release model of message element: $\tau_{\mathrm{ij}}(\mathrm{t}+\mathrm{n})=(1-\rho) \tau_{\mathrm{ij}}(\mathrm{t})$ 


\section{Mathematical model of logistic car distribution}

Suppose there are several destinations of logistic distribution, the route of logistic distribution is already known, the maximum cargo capacity of logistic distribution car is known, it requires logistic distribution car to start from the beginning and visit logistic distribution destination to complete distribution tasks and then return to distribution station on condition that distribution car does not exceed maximum traveling distance, then solves the problems that requires distribution car to use the minimum cars to find out the optimal distribution route ${ }^{[5-6]}$ on condition that distribution car does not exceed maximum traveling distance. logistic car distribution can be described as the following mathematical model:

$$
\begin{aligned}
& \text { Target function: } \operatorname{minZ}=\left\{\sum_{\mathrm{i}} \sum_{\mathrm{j}} \sum_{\mathrm{k}} \mathrm{c}_{\mathrm{ij}} \mathrm{x}_{\mathrm{ijk}}, \sum_{\mathrm{j}} \sum_{\mathrm{k}} \mathrm{x}_{0 \mathrm{jk}}\right\} \\
& \text { Of which, } x_{i j k}=\left\{\begin{array}{lr}
1 & \text { car passing path }(i, j) \\
0 & \text { car does not pass path }(i, j)
\end{array}\right. \\
& \text { constraint condition: } \\
& \text { constraint condition a: } \sum_{\mathrm{i}} \mathrm{d}_{\mathrm{i}} \mathrm{y}_{\mathrm{ki}} \leq \mathrm{D}, \forall \mathrm{k} \\
& \text { constraint condition b: } \sum_{\mathrm{i}} \sum_{\mathrm{j}} \mathrm{d}_{\mathrm{i}} \mathrm{y}_{\mathrm{ki}} \leq \mathrm{L}, \forall \mathrm{k} \\
& \text { constraint condition c: } \sum_{\mathrm{k}} \mathrm{y}_{\mathrm{ki}}=\mathrm{L}_{,}, \mathrm{i} \in \mathrm{V} \\
& \text { constraint condition d: } \sum_{\mathrm{i}} \mathrm{x}_{\mathrm{ijk}}=\mathrm{y}_{\mathrm{kj}} \mathrm{j} \in \mathrm{V}, \forall \mathrm{k} \\
& \text { constraint condition e: } \sum_{\mathrm{j}} \mathrm{x}_{\mathrm{ijk}}=\mathrm{y}_{\mathrm{kj}}, \mathrm{i} \in \mathrm{V}, \forall \mathrm{k} \\
& \text { constraint condition f: } \quad \sum_{\mathrm{i}} \sum_{\mathrm{jeS} \times \mathrm{S}} \mathrm{x}_{\mathrm{ijk}} \leq|\mathrm{S}|-1, \mathrm{~S} \subseteq \mathrm{V} \\
& \text { Of which, } x_{i j k}, y_{k i} \in\{0,1\}, i, j \in V, \forall k
\end{aligned}
$$

Target function indicates the length of the shortest distribution route and minimum car, constraint condition a indicates cargo capacity of car k can not exceed its maximum capacity, constraint condition b indicates that every task should be completed by every car, constraint condition c indicates there are totally $\mathrm{L}$ distribution cars, constraint condition $\mathrm{d}$ and e indicate the internal relations of variable, constraint condition $\mathrm{f}$ indicates to eliminate the route away from logistic center.

\section{Application of improved ant colony algorithm to solve logistic distribution route}

\subsection{Defect of traditional ant colony algorithm and proposal of improved way}

The traditional ant colony algorithm will usually be crowded in route with plenty of information, which will cause problems such as slow convergence rate, and it can not find out the global optimal route etc. So it is necessary to make improvement ${ }^{[7-8]}$ on choice mechanism of traditional ant colony algorithm, while genetic algorithm can combine preferential with random information together, every generation can retain the best genes of the last generation on searching logistic distribution route and forms the new fine species of the next generation, prevent Immature convergence of algorithm, guarantee route search result has global optimality. Therefore, this paper puts forward the solution method of new logistic distribution of combining ant colony algorithm with genetic algorithm.

5.2 The key realization steps of genetic algorithm

\subsubsection{Coding}

Making coding for logistic distribution model is the base to carry out genetic algorithm intersection and variation operation, firstly, we should carry out coding. This paper does not adopt the usual binary coding on logistic distribution coding, while it directly adopts natural number 
coding. Every natural number represents the number of customer; $\mathrm{n}$ natural numbers forms one gene chain and represents one route.

\subsubsection{Population initialization}

Command $W_{i}$ indicate one gene, it is composed of natural number by customer number, the application vector $\left(W_{1}, W_{2}, \ldots W_{n}\right)$ indicates one chromosome, this paper adopts random way to generate chromosome; random chromosome composes the initial population.

\subsubsection{Fitness calculation}

In order to make chromosome evolve toward optimal direction, it needs to choose one better fitness calculation function. It can evaluate the individual advantage and disadvantage through this function. It uses value of fitness function to evaluate individual advantage and disadvantage, the bigger of individual fitness, the larger of its performance; otherwise it will become worse. The optimization target has already been given by target function: $\operatorname{minZ}=\left\{\sum_{\mathrm{i}} \sum_{\mathrm{j}} \sum_{\mathrm{k}} \mathrm{c}_{\mathrm{ij}} \mathrm{x}_{\mathrm{ijk}}, \sum_{\mathrm{j}} \sum_{\mathrm{k}} \mathrm{x}_{0 \mathrm{jk}}\right\}$.

This paper adopts the following formula to make fitness calculation:

$$
\operatorname{Fit}(\mathrm{f}(\mathrm{x}))=\xi \times \frac{\mathrm{Z}^{\prime}}{\mathrm{Z}}
$$

Of which, $\xi$ is one adjustable constant, $\mathrm{Z}^{\prime}$ indicates the target function value corresponds to the best individual in current population, $\mathrm{Z}$ indicates the target function value of required individual.

\subsubsection{Selecting operation}

Selection strategy has very important effect on performance of genetic algorithm, this paper adopts roulette wheel selection strategy, and its core idea is as follows: suppose the individual number of population is $N$, command $\sum_{i=1}^{n} f_{i}$ indicate fitness sum of population, $f_{i}$ indicates the fitness value of the $\mathrm{i}$ chromosome in population, the probability $\mathrm{P}_{\mathrm{i}}$ of it to generate offspring is as follows:

$$
P_{i}=\frac{f_{i}}{\sum_{i=1}^{n} f_{i}}
$$

\subsubsection{Interlace operation}

Interlace operation is very important in genetic algorithm; it can maintain performance of good individual to certain degree and search new gene space. In this topic, this paper adopts some mapping intersection to realize interlace operation. It randomly generates positive 2 integer that less than length of chromosome and regards it as intersection point of chromosome to determine one matching section, and then generates 2 sub individuals.

\subsubsection{Mutation operation}

Mutation operation can realize partial and random search, making genetic algorithm to have partial and random search ability, guarantee population diversity and avoid it falling into locally optimal solution. This research adopts random and mutation operation for many times, this kind of operation only needs to randomly choose 2 genes to make position replacement to achieve it, its realization is very simple.

5.3 Realization of ant colony algorithm based on genetics

The realization core of ant colony algorithm based on genetics is to add mechanism of genetic algorithm on the basis of basic ant colony algorithm. Firstly, it generates population data of initial diversity by iteration, and then genetic algorithm chooses operation, interlace operation and mutation operation, which provides new data after iteration for ant colony algorithm function, avoid ant colony algorithm falling into locally optimal solution. The detailed procedure of algorithm realization is indicated by diagram 2 : 


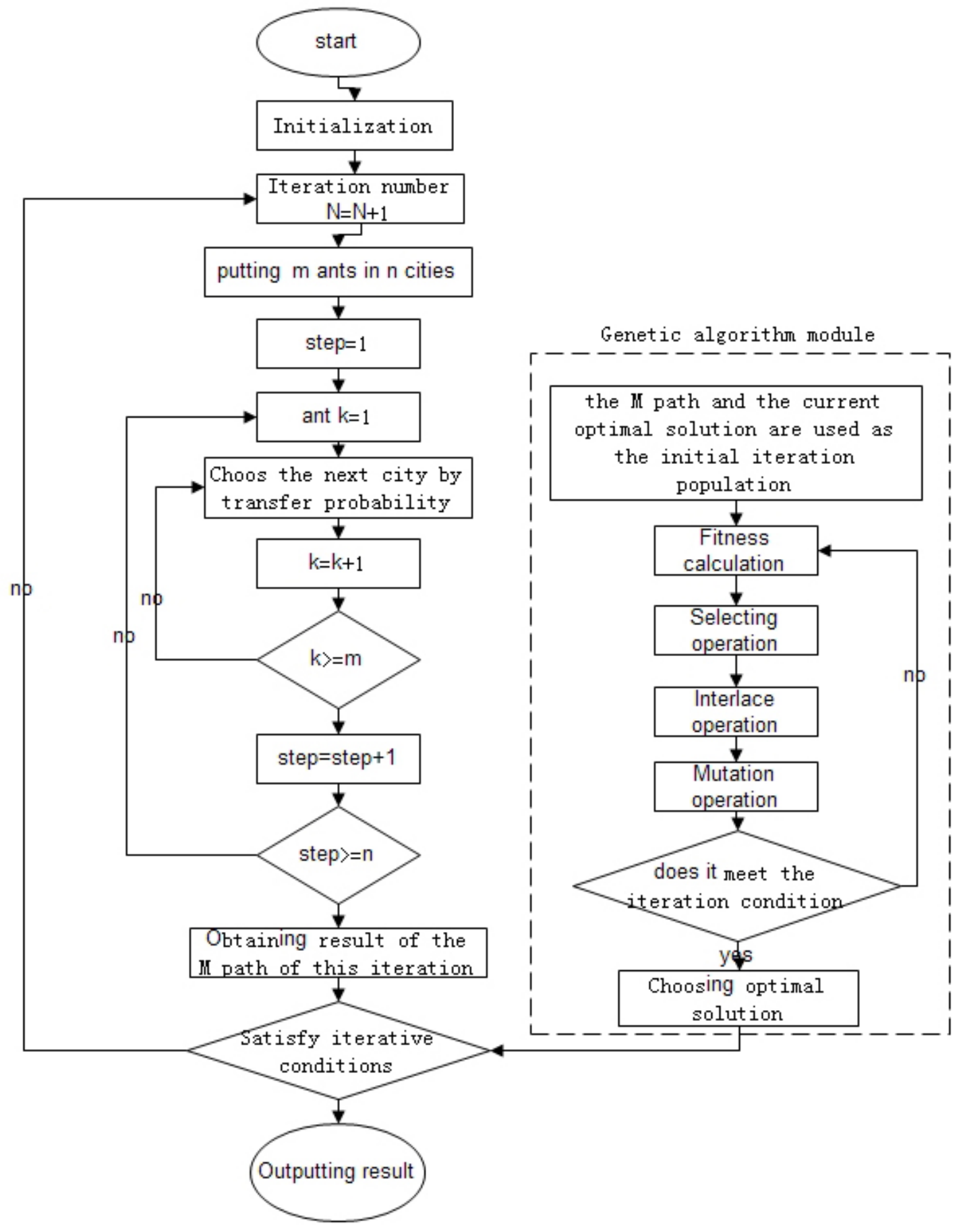

Diagram 2 Realization flow chart of ant colony algorithm based on genetics

\section{Simulation experiment analysis}

In order to test performance of ant colony algorithm after improvement, this paper designs simulation experiment to analyze ant colony algorithm after improvement.

Suppose there are 19 target destinations and the maximum load of distribution car is 9 , the coordinate of distribution center is $(0,0)$, the coordinate and load of target distribution point are indicated by the following table: 
Table 1 Data sheet of logistic test

\begin{tabular}{|c|c|c|c|c|c|c|c|}
\hline Target point of distribution & 1 & 2 & 3 & 4 & 5 & 6 & 7 \\
\hline Coordinate of target point & $(3,4)$ & $(-3,0)$ & $(2,0)$ & $(1,-3)$ & $(2,-1)$ & $(2,1)$ & $(1,-4)$ \\
\hline Goods weight & 0.2 & 2.4 & 1.9 & 2 & 0.7 & 0.5 & 2.2 \\
\hline Target point of distribution & 8 & 9 & 10 & 11 & 12 & 13 & 14 \\
\hline Coordinate of target point & $(0,-1)$ & $(0,3)$ & $(-2,-1)$ & $(-3,-3)$ & $(3,-1)$ & $(-4,0)$ & $(-4,-1)$ \\
\hline Goods weight & 1.5 & 1.8 & 2 & 0.8 & 1.5 & 1 & 2.5 \\
\hline Target point of distribution & 15 & 16 & 17 & 18 & 19 & & \\
\hline Coordinate of target point & $(-3,2)$ & $(-1,-1)$ & $(1,3)$ & $(1,-2)$ & $(1,-1)$ & & \\
\hline Goods weight & 3.1 & 0.1 & 0.6 & 3 & 1.7 & & \\
\hline
\end{tabular}

Under environemnt of the same software, hardware and parameter setting, it respectively operates the traditional ant colony algorithm and improved ant colony algorithm and gets the following technical parameters:

Table 2 Technical and performance parametr table of algorym and opeation

\begin{tabular}{|c|c|c|c|c|c|c|c|c|c|c|c|c|}
\hline $\begin{array}{c}\text { Algorithm } \\
\text { classificatio } \\
n\end{array}$ & $\begin{array}{c}\text { experimen } \\
\text { t number }\end{array}$ & 1 & 2 & 3 & 4 & 5 & 6 & 7 & 8 & 9 & 10 & $\begin{array}{c}\text { Averag } \\
\text { e }\end{array}$ \\
\hline \multirow{4}{*}{$\begin{array}{l}\text { Traditional } \\
\text { ant colony } \\
\text { algorithm }\end{array}$} & $\begin{array}{c}\text { the } \\
\text { shortest } \\
\text { distributio } \\
\text { n distance }\end{array}$ & 43.8 & $\begin{array}{c}41.8 \\
6\end{array}$ & 43.5 & $\begin{array}{c}41.9 \\
9\end{array}$ & 43.4 & $\begin{array}{c}44.0 \\
1\end{array}$ & $\begin{array}{c}42.5 \\
8\end{array}$ & $\begin{array}{c}41.8 \\
6\end{array}$ & $\begin{array}{c}43.2 \\
1\end{array}$ & 43.1 & 42.9 \\
\hline & $\begin{array}{c}\text { the } \\
\text { number of } \\
\text { distributio } \\
\text { n car }\end{array}$ & 4 & 4 & 4 & 4 & 4 & 4 & 4 & 4 & 4 & 4 & 4 \\
\hline & test time & 2.4 & 2.2 & 2.4 & 2.3 & 2.5 & 2.8 & 2.4 & 2.1 & 2.6 & 2.4 & 2.4 \\
\hline & $\begin{array}{c}\text { difference } \\
\text { with the } \\
\text { optimal } \\
\text { solution }\end{array}$ & 1.94 & 0 & 1.64 & 0.13 & 1.54 & 2.14 & 0.72 & 0 & 1.41 & 1.24 & 1.04 \\
\hline \multirow{4}{*}{$\begin{array}{l}\text { Improved } \\
\text { ant colony } \\
\text { algorithm }\end{array}$} & $\begin{array}{c}\text { the } \\
\text { shortest } \\
\text { distributio } \\
\text { n distance }\end{array}$ & $\begin{array}{c}43.3 \\
9\end{array}$ & 43.1 & $\begin{array}{c}41.8 \\
6\end{array}$ & $\begin{array}{c}43.2 \\
1\end{array}$ & $\begin{array}{c}41.8 \\
8\end{array}$ & $\begin{array}{c}42.5 \\
8\end{array}$ & $\begin{array}{c}42.7 \\
3\end{array}$ & $\begin{array}{c}41.8 \\
6\end{array}$ & $\begin{array}{c}41.8 \\
6\end{array}$ & $\begin{array}{c}41.9 \\
4\end{array}$ & 42.44 \\
\hline & $\begin{array}{c}\text { the } \\
\text { number of } \\
\text { distributio } \\
\mathrm{n} \text { car }\end{array}$ & 4 & 4 & 4 & 4 & 4 & 4 & 4 & 4 & 4 & 4 & 4 \\
\hline & test time & 2.4 & 2.19 & 2.2 & 2.07 & 2.5 & 2.19 & 2.14 & 1.3 & 2.4 & 2.23 & 2.16 \\
\hline & $\begin{array}{l}\text { difference } \\
\text { with the } \\
\text { optimal } \\
\text { solution }\end{array}$ & 1.53 & 1.24 & 0 & 1.35 & 0.02 & 0.72 & 0.87 & 0 & 0 & 0.03 & 0.576 \\
\hline
\end{tabular}

Compared with the known and the shortest distribution route distance 41.86, traditional ant colony algorithm gets optimal solutions for 2 times, the improved ant colony algorithm gets optimal solution for 3 times, the average operation time of traditional ant colony algorithm is 2.4 seconds, the average operation time of improved ant colony algorithm is 2.16 seconds, the average smallest distance of traditional ant colony algorithm is 42.9 , the difference with the current known optimal is 1.04, the average smallest distance of improved ant colony algorithm is 42.44 , the difference with the current known optimal value is 0.576 . From the above test results, it can be seen that ant colony algorithm after improvement has high search efficiency and time performance in aspect of solving the shortest route of logistic. 


\section{Conclusion}

With the drastic quick development of logistic industry, dispatch and management problems of logistic distribution car are becoming increasingly complicated, it is impossible to get the optimal route by the traditional precise calculation. This paper uses improved ant colony algorithm to solve logistic distribution route as well as makes simulated and test. Test indicates that ant colony algorithm after improvement has better advantage and performance in solving global optimal solution. Applying it into dispatch and management of logistic distribution car has stronger economic benefit and practical value.

\section{References}

[1] Gao Gengjun, Huang Wei. Goods Distribution Problem in Modern Logistic Center fJI.Journal of Southeast China University (natural science version), 2001, (06)

[2] Cheng Shidong, Guan Hongzhi, Liu Xiaoming. Research on City Logistic Distribution Model [J]. Road Traffic and Safety, 2004, (03)

[3] Li Yong, Duan Zhengcheng. Solution to TSP Problem by Dynamic Ant Colony Algorithm [J].Computer Process and Application, 2003.39(17):

103-106

[4] Cui Xueli, Ma Liang. Resaerch on VRP Ant Colony Algorithm with Limitations in Out of Stock [J].Journal of Shanghai University Of Technology, 2003, 25 (1) : 39-45.

[5] Liu Yunzhong, Yi Beiyu. Application Resarch on Ant Algorithm in Car Route [J].Information and Control, 2004:249-252.

[6] Duan Haibin. Theory and Application of Ant Colony Algorithm [M].Beijing: Science Press, 2005

[7] Li Jun, Guo Yaohuang. Theory and Method of Logistic Distribution Car Dispatch [M].Beijing: China Material Press, 2001. 2-7 , 76-77

[8] Zeng Chuanhua. Logistic Management and Information System [M].Beijing: Tsinghua University Press, 2007, 